\title{
ASSOCIATION OF MISOPROSTOL, MOEBIUS SYNDROME AND CONGENITAL CENTRAL ALVEOLAR HYPOVENTILATION \\ CASE REPORT
}

MAGDA LAHORGUE NUNES*, MAURICIO A. G. FRIEDRICH**, LUIZ FERNANDO LOCH***

\begin{abstract}
We report a case showing the association of Moebius syndrome, the use of misoprostol during pregnancy and the development of central congenital alveolar hypoventilation. Pathophysiological aspects of these three diseases are discussed and also the unfavorable prognosis of this association.
\end{abstract}

KEY WORDS: apnea, congenital central alveolar hypoventilation, Moebius syndrome.

\begin{abstract}
Associação de misoprostol, síndrome de Moebius e hipoventilação central congênita: relato de caso
RESUMO - Descrevemos o caso de um paciente com Síndrome de Moebius associada ao uso de misoprostol durante a gestação. A criança necessitou de suporte ventilatório desde o primeiro dia de vida e evoluiu com quadro de hipoventilação alveolar central congênita, persistindo dependente de ventilação mecânica. São discutidos aspectos fisiopatológicos que poderiam justificar a comorbidade destes três eventos, assim como o prognóstico reservado desta associação.
\end{abstract}

PALAVRAS-CHAVE: apnéia, hipoventilação alveolar central congênita, síndrome de Moebius.

Moebius syndrome is clinically characterized by congenital nonprogressive facial diplegia and restricted lateral eyes movements. It is usually bilateral and can be followed by other cranial nerves palsy (third, fifth, ninth and tenth). It is usually associated with craniofacial malformation (micrognathia, bifid uvula, cleft palate, epicanthus, external ear) and other malformations (talipes equinovarus, syndactily) ${ }^{1,2}$. The etiology of this syndrome was speculated to be a congenital absence of the motor nuclei of the abducens and facial nerves, but genetical and environmental factors can also be involved. Exposure to infections, alcohol, cocaine, thalidomide or misoprostol were also related in association with Moebius syndrome. It was found in most cases that this syndrome can be the result of infarction of brainstem nuclei during fetal life ${ }^{3-5}$. It was also showed in some cases evidences of vascular malformations as capillary hemangiomas in mesencephalic and pontine segments ${ }^{2}$.

Congenital central alveolar hypoventilation syndrome (CCAHS) is generally recognized in the first days of life. Symptoms, among others, may include cyanosis, apnea, and sudden respiratory failure. Central hypoventilation is characterized by: hypoventilation during sleep, no or minimal ventilatory and arousal responses to hypercarbia and hypoxia during sleep, nonresponsiveness to respiratory stimulants, unawareness of hypoxia, adequate baseline ventilation during wakefulness, absent or negligible response to hypoxia and hypercarbia while awake ${ }^{7}$. A polysomnography is needed

*Professora Adjunta de Neurologia, Faculdade de Medicina (FAMED) da Pontificia Universidade Católica do Rio Grande do Sul (PUCRS), Serviço de Neurologia do Hospital São Lucas da PUCRS; **Mestrando, Curso de Pós Graduação FAMED - PUCRS; ***Unidade de Terapia Intensiva Pediátrica , Hospital da Universidade Luterana do Brasil (ULBRA). Aceite: 28-outubro-1998.

Dra. Magda Lahorgue Nunes - Division of Neurology, São Lucas Hospital PUCRS -Av. Ipiranga 6690/322. 90610-000 Porto Alegre RS - Brasil Fax: 051339 4936. E-mail: magdalahorgue@ conex.com.br 


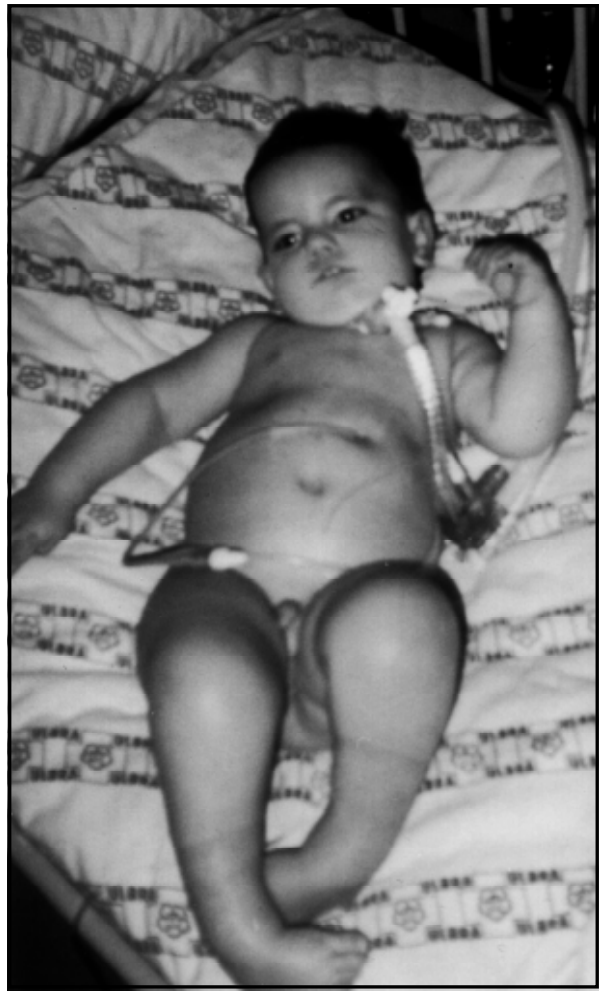

Fig 1. This picture shows the patient with around 10 months. We can observe the facial features of Moebius syndrome and equinovarus feet.

to confirm the diagnosis. Other disorders such as primary lung disease, myopathy and upper airway obstruction should be excluded before this diagnosis.
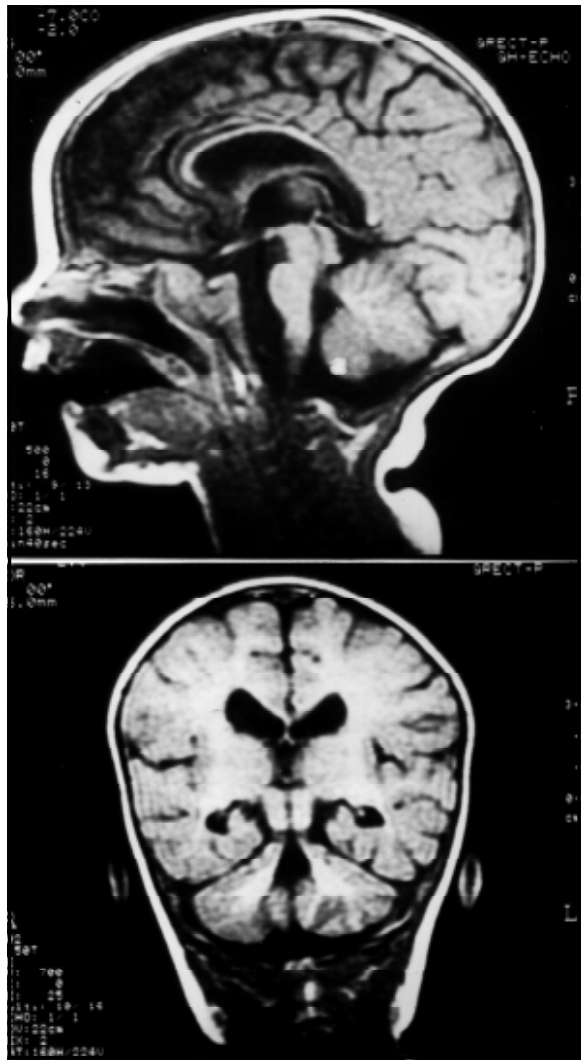

Fig 2. Nuclear magnetic resonance image in sagittal view (a) shows corpus callosum hypoplasia and enlarged subarachnoid space at posterior fossa, coronal view $(b)$ evidences ventricular dilation and reduction of volume in frontal lobes.

\section{CASE REPORT}

The subject of this report is a 14-months-old white boy, born by a cesarean section. Intrauterine growth retardation and severe perinatal asphyxia were reported. Birth weight $2730 \mathrm{gm}$, for a gestational age of 39 weeks. The mother referred the use of misoprostol, as an abortifacient, in the eighth week of gestation.

Clinical examination showed expressionless face, facial diplegia, high palatal arch and bilateral equinovarus foot (Fig 1). He was put on mechanical ventilation since the first day of life, unsuccessfully extubations were tried. For some periods, after the first month of life, he had spontaneous respiratory efforts, while awake. When sleeping he needed CPAP. The follow up showed increased necessity of ventilatory support even during wake state. After tracheotomy and gastrostomy, he is still in mechanical ventilation.

A computed tomographic scan performed at 3 days showed diffuse hypondense lesions and enlarged subarachnoid space at posterior fossa. Diffuse low voltage pattern was registered in the EEG and brainstem evoked potential showed bilateral bulbar delay. Later a somatosensory evoked potential showed normal latencies and an electroneuromyography excluded muscle diseases or peripheral neuropathy. Single photon emission tomography showed normal cerebral perfusion. At 8 months of age a magnetic resonance image demonstrated symmetrical ventricular dilation, reduction of frontal lobes and corpus callosum hypoplasia (Fig 2). Two polysomnographies were performed, respectively at 7 and 9 months, both showed central apneas and minimal or absent respiratory drive (Fig 3). 


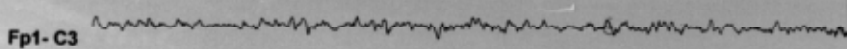

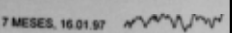

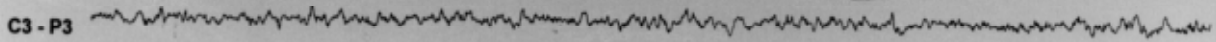

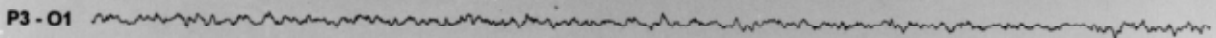

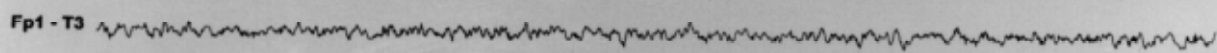

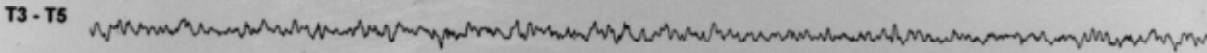

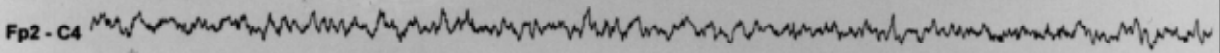

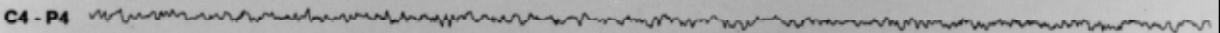

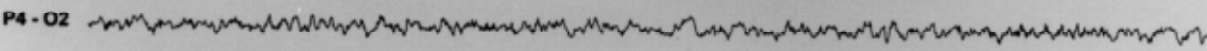

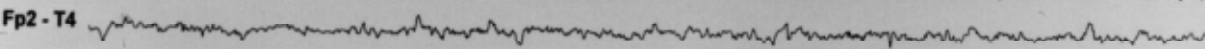

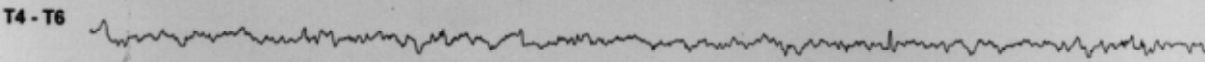
EOG Prom

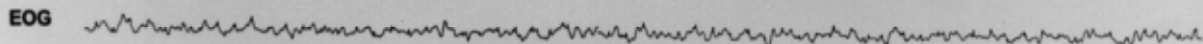

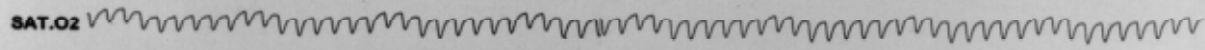
NASAL

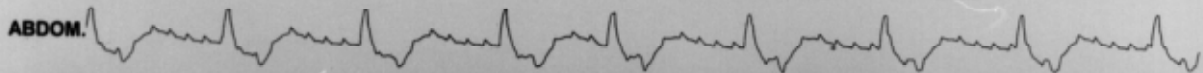

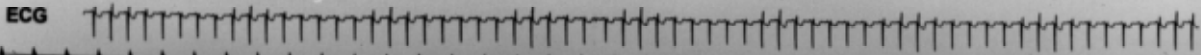
$+,+,+,+,+,+,+,+,+,+,+,+,+,+,+,+,+,+,+,+,+$,
\end{abstract}

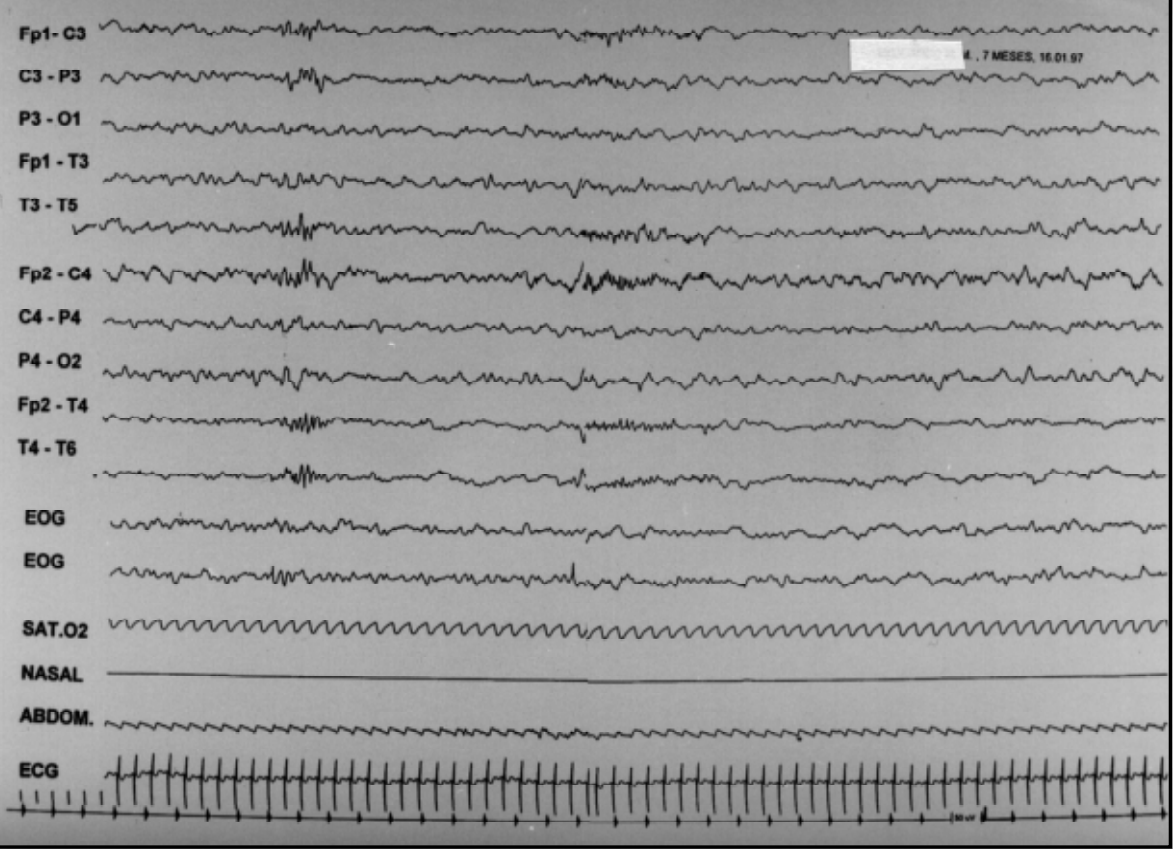

Fig 3. Polysomnography performed at 7 months, (a) with ventilatory support CPAP, $(b)$ when the ventilatory support is disconnected. We do not see any respiratory effort. 


\section{DISCUSSION}

The association of Moebius syndrome and respiratory failure do not occur very often, and around 15 cases were described in the literature. All the cases showed necrosis/gliosis of the paramedian tegmentum of the medulla and pons, suggesting a mechanical injury to the brainstem respiratory center ${ }^{4}$. Our patient showed indirect evidences of brainstem injury by evoked potentials and neuroimage. A possible teratogenic mechanism for Moebius syndrome after the use of misoprostol was also raised before. The hypothesis discussed suggests that ischemic events can follow contractions induced by misoprostol and affect cranial nerve nuclei 6 and 7, resulting in the facial diplegia ${ }^{8}$.

Gonzalez et al. ${ }^{9}$, in a recent publication, studied 42 Brazilian children with congenital abnormalities associated to misoprostol misuse during pregnancy, they found arthrogryposis and terminal transverse - limb defects as the most distinctive phenotype. No cases of CCAHS were reported.

We could assume that our patient developed a Moebius syndrome related to the use of misoprostol and followed unfavorably probably by the evidence of brainstem injury leading to CCAHS.

The association of these three events, to our knowledge, have not been described before, and we would like to raise attention to the unfavorable prognosis of this triad.

\section{REFERENCES}

1. Kumar D. Moebius syndrome. J Med Genet 1990;27:122-126.

2. Sarnat HB. Dysgenesis of the central nervous system. In Berg BO (ed). Principles of child neurology. New York: McGrawHill,1996;629-649.

3. Gonzalez CH, Vargas FR, Perez AB, et al. Limb deficiency with and without Moebius sequence in seven Brazilian children associated with misoprostol use in the first trimester. Am J Med Genet 1993;47:59-63.

4. Igarashi M, Rose DF, Storgion SA. Moebius syndrome and central respiratory dysfunction. Ped Neurol 1997;16:237-240.

5. Towfighi J, Marks K, Palmer E, Vannucci R. Moebius syndrome: neurophatologic observations. Acta Neuropathol 1979;48:11-17.

6. D'Cruz OF, Swisher CN, Jaradeh S, et al. Moebius syndrome: evidence or a vascular etiology. J Child Neurol 1993;8:260-265.

7. Ariagno RL, Apnea. In Behrman RE. (ed), Nelson textbook of pediatrics (Update 6). London: W.B. Saunders, 1994:1-12.

8. Shepard TH. Moebius syndrome after misoprostol: a possible teratogenic mechanism. Lancet 1996;346:780.

9. Gonzalez CH, Marques-Dias MJ, Kim CA, Sugayama SMM, Da Paz JA. Congenital abnormalities in Brazilian children associated with misoprostol misuse in first trimester of pregnancy. Lancet 1998;351:1624-1627. 